\title{
Using ICT to Improve on Governance in Developing Countries: The Case of Zambian Parliamentarians
}

\author{
Francis Kalekanya Ng'uni' ${ }^{1}$ Jackson Phiri² \\ ${ }^{1}$ School of Science, Engineering and Technology, Mulungushi University, Kabwe, Zambia \\ ${ }^{2}$ Department of Computer Sciences, School of Natural Sciences, University of Zambia, Lusaka, Zambia \\ Email: ngunikale@gmail.com, jackson.phiri@cs.unza.zm
}

How to cite this paper: Ng'uni, F.K. and Phiri, J. (2019) Using ICT to Improve on Governance in Developing Countries: The Case of Zambian Parliamentarians. Open Journal of Business and Management, 7, 1744-1765.

https://doi.org/10.4236/ojbm.2019.74121

Received: July 24, 2019

Accepted: September 23, 2019

Published: September 26, 2019

Copyright $\odot 2019$ by author(s) and Scientific Research Publishing Inc. This work is licensed under the Creative Commons Attribution International License (CC BY 4.0).

http://creativecommons.org/licenses/by/4.0/

\begin{abstract}
More and more mobile applications are being developed to make it possible for services available on desktop computers to be accessed on mobile devices. Further, the market for such applications grows bigger every day. The discussion on the use of mobile technology in data collection has been motivated by the advancement of modern cellular technologies that enable mobile devices to have more memory, processing speed and visual display capacity. Furthermore, mobile phones are more portable and have longer-lasting battery life, thereby being more supportive of remote collection of data in various geographical locations than laptop computers. The aim of this study was to ascertain the challenges based on the Technology Acceptance Model (TAM) those members of parliament face when interacting with electorates from their respective constituencies and to propose a model to address these challenges. A baseline study was conducted from a selected number of constituencies. Questionnaires were distributed based purposive sampling. The data collected from the questionnaires were analyzed using SPSS descriptive analysis method based on security of automated systems, perceived usefulness and perceived ease of use. The study revealed that the two factors perceived usefulness and perceived ease of use have a significant impact on the adoption of the proposed automation of e-services by model.
\end{abstract}

\section{Keywords}

Mobile Application, Electorate, Member of Parliament, Data Collection, Constituency

\section{Introduction}

Mobile applications are slowly becoming many people's platform of choice for 
the provision of goods and services. The growth of mobile technology in recent years, which has been quite dramatic and exciting, has been opening doors for technology experts and businesses to present themselves in front of their audiences on a truly global scale. In Zambia's rural constituencies, socio-economic and geographical barriers have hindered access to data and adversely affected data collection methods, which are mostly manual and paper-based. Further, the data collected through manual methods are neither standardised nor reliable, leading to underreporting and undermined decision-making at the managerial level. The demand for quality data is as high as the frequency with which it is used to anchor decision-making processes that impact socio-economic and environmental behaviour monitoring in the constituencies. The data is difficult to process for analytical and data mining purposes. The use of mobile technology in data collection has been anchored by the advancement of cellular technologies, leading to enhanced capacity of devices in memory, processing speed and visual display.

Generally mobile applications for interaction between stake holder and leaders have been on the increase in developing countries. Ariel Phiri for example in [1] was looking mobile application usage in business supply chain while Annie Mpolokoso in [2] was looking at interaction between traditional leaders and subjects in land management through mobile applications. In this study, we will be looking at mobile application usage by parliaments and electorates to improve communication and governance issues in developing countries in African. This study looks at the view of improving information flow between Members of Parliament and electorates based on mobile technologies. In spite of the studies undertaken on ways of improvement on interaction between the concerned parties, there is limited research in Zambia in view of mobile application development to address that identified gap.

This study is significant in trying to bridge the gap of interaction and also information flow between Members of Parliament and the electorates in developing countries. This study will be of great help not only to the legislative organ of the government but also to the other government departments still implementing e-governance in developing countries such as Zambia. This article proposes the development of a cloud-based mobile application that will enable Zambian parliamentarians to interact with their electorates.

The rest of the paper is organised as follows: this section which is Section 1 gives the introduction to the study while Section 2 is the literature review. In Section 3, we give the related works, in Section 4 the research methodology and the results in Section 5. The discussion and conclusion are given in Section 6 and Section 7 respectively.

\section{Literature Review}

First, Governance is a critical factor in accelerated and sustainable economic growth and development. It is the exercise of power for the management of a na- 
tion's affairs [3]. In this regard, the concept of good governance "is emerging as a principle of international law" [4] to which African countries and their agencies are expected to adhere. Unfortunately, the current method of governance results in local policy outcomes that are less connected to the actions of central governments and more connected to conditional partnerships, memberships, networks or private and informal relations [5].

\subsection{E-Governance}

Governments the world over have incorporated the use of information and communication technologies (ICTs) into governmental processes, leading to the birth and popularization of the concept of e-governance. E-Governance has been defined, among many other ways, as a technology-mediated service that facilitates a transformation in the relationship between a government and its citizens; a technology-mediated relationship between citizens and their governments, from the perspective of potential electronic deliberation over civic communication, over policy evolution and in democratic expressions of the citizen will [6]. E-Governance also makes administrative processes transparent, efficient and convenient. The widespread use of ICTs offers governments and citizens the ability to address traditional development and governance issues in a new and innovative fashion. From the governmental perspective, ICTs are a catalytic tool in the provision of services to marginalized populations, thus contributing to the attainment of the Millennium Development Goals (MDGs) and enhancement of transparency and accountability. Meanwhile, citizens and stakeholders can benefit by having access to new communication channels and "louder" voices in public decision- and policy-making processes.

ICTs have advanced considerably, including in Africa, and broken through to social and political life. In the face of numerous advantages they offer, such as speed, cost reduction and wider reach, these technologies are now crucial to the public and private sectors, and civil society organizations (CSOs) in their internal communication, communication with citizens and provision of services and goods to the public. Therefore, ICTs can enhance citizen participation and interaction between citizens and elected officials, and among citizens (e-participation).

\subsection{M-Government}

M-governance can be considered a subset that facilitates e-governance or as a form of governance on its own [7]. Mobile governance is the use of mobile technologies (such as SMS, USSD) in the domains of citizen participation, provision of public services, information and public awareness to reach wider population segments as compared to those currently accessing the Internet [8].

Mobile technology has been the main drive in expanding Governments ability in offering and delivering citizens and business services as observed in developing countries. This is so due to the fact that for a long time, there have been limitations and to some extent non availability of communication which con- 
strains social improvements and also economic development. As a result, countries that have developed e-governance services have an opportunity to tackle related digital divide concerns and suffice to say that these developments are powerful and transformational capacities in accessing e-governance services increase active citizen participation in Government operations and hence help in transitioning beyond the concentration of e-governance on commerce and e-taxation to improving internal operations. This amalgamation of mobile devices and new media applications which support quick access to integrated data, location based services, and hence empowered citizens from any place at any time is therefore the cornerstone of the emerging impact of mobile governance [9]. Mobile governance has the potential of delivering real-time location-based information on demand, performing transactions, and most importantly use extant mobile network to reach citizens and provide new customized services [10].

\subsection{E-Governance at National Assembly of Zambia}

Since 2002, the National Assembly of Zambia has been implementing a reform programme called "Taking Parliament Closer to the People". The reforms entail a paradigm shift in the way the National Assembly communicates with its stakeholders, such as Members of Parliament, the cooperating partners and constituents, in the 156 constituencies of the country, almost half of which are geographically remote.

Data collection is an important activity for remote constituencies, as Members of Parliament (MP's) and other policy makers need accurate and "fresh" data to improve the quality of services they provide in those constituencies. Further, data is critical to determining service coverage and shortcomings. Therefore, it helps in the proper allocation of resources. In resource-limited settings like in the developing world, evidence-based decision-making is important to the prudent use of the available resources.

\subsection{Technology}

Technology is a concept that is difficult to interpret, observe and evaluate as noted in [11]. Despite the extensive research conducted on the subject, the available literature is fragmented according to the specialties. Generally, there is no commonly accepted paradigm [12]. However, the use of wireless electronic communication over 100 years ago was the starting point of the electronic era. The advances in technology have brought many changes to people's lifestyles and pervaded every aspect of human life, be it in entertainment, education, the economy, governance or health [13]. Technology has also improved business processes and increased productivity, leading to a scramble for the best technologies among organisations and nations. Technology is also considered a vehicle for disseminating knowledge and services [10] [14].

\subsection{Technology Acceptance}

Technology acceptance is the process of people accepting and adopting a tech- 
nology for use [15]. [16] describes user technology acceptance as a demonstrable willingness within a user group to employ IT for the tasks it is designed to support. Acceptance can, therefore, be seen as being more of a user attribute in the use of technology, and as a critical factor in determining the success or failure of any technology. Further, acceptance is conceptualised as an outcome variable in a psychological process that users go through in making decisions about technology [16]. In other words, technology is of little value if it is not accepted and used [17]. The rejection or acceptance of technology has been a prominent topic in the field of information system (IS), marketing and social science Services [10] [18].

\subsection{Technology Acceptance Model and Theories}

A model is a systematic description of a system, a theory or a phenomenon that accounts for the known or inferred properties of what is described, which may be used to further study the characteristics. It is also any abstract representation of a portion of the real world constructed for the purpose of understanding, explaining, predicting or controlling the phenomenon being investigated [19]. Many technology acceptance models and theories have been developed over the years. They include the following:

\subsubsection{Theory of Reasoned Action}

Fishbein [19] adduces that the Theory of Reasoned Action (TRA), whose roots are in social psychology, proposes that individuals' attitudes and subjective norms influence their behavioural intentions towards technology. The theory proposes three general constructs that underpin the interaction between people and technology, namely behavioural intention (BI), attitude (A) and subjective norm (SN). According to the theory, people's BIs is the sum of their attitude and subjective norms, and the possibility of a BI being converted to action corresponds to the strength of the intention. According to the theory, individuals would adopt any technology if they saw the positive benefits (outcomes) associated with doing so [19] as shown in Figure 1.

\subsubsection{Unified Theory of Acceptance and Use of Technology}

The Unified Theory of Acceptance and Use of Technology (UTAUT) was formulated in a quest to harmonise earlier technology adoption models, namely TRA, Theory of Planned Behaviour (TPB), the Technology Acceptance Model (TAM), the Motivational Model, Personal Computer (PC) Utilisation, Diffusion of Innovation (DOI) and the Social Cognitive theories [20]. Venkatesh et al. [21] examined eight technology acceptance models and used the findings to identify the four core determinants of intention and usage, and up to four moderators of key relationships. The four determinants are social influence, performance expectancy, effort expectancy and facilitating conditions (see Figure 2). The validation of the UTAUT was conducted to conclude a $70 \%$ variance in usage intention [21]. 


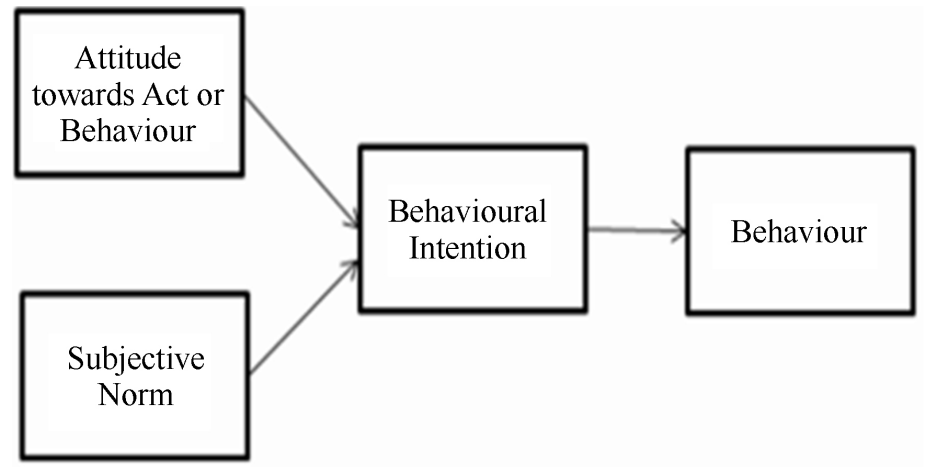

Figure 1. Theory of reasoned action (TRA), Fishbein and Adjen (1975).

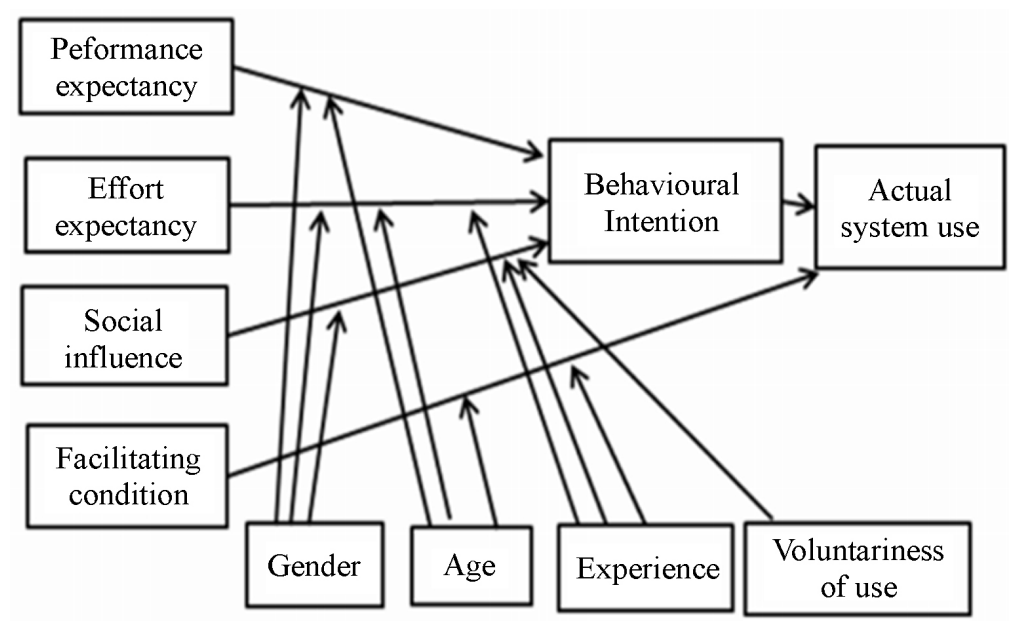

Figure 2. UTAUT (Venkatesh et al. 2003).

\subsubsection{Technology Acceptance Model}

Evolving from the Theory of Reasoned Action (TRA), The Technology Acceptance Model (TAM) was the first in which psychological factors that affect technology acceptance were mentioned. The theory developed and validated better measures through for predicting and explaining technology use [20]. The model suggests that when users are presented with a new technology, a number of factors influence their decision on how they will use the technology [22]. The "Perceived usefulness" and "perceived ease of use" for predicting extent of adoption of technologies at individual level is the strength that gives the model to be adopted in many technological studies [20] as shown in Figure 3.

\subsection{Mobile Application Development}

Statista [23] explores the general idea that Mobile Application Development (MAD) is the process by which applications (Apps) are developed for small, low-power hand-held devices. Though the model is similar to software engineering, it also presents additional requirements for which the traditional software development process has to be customised. Mobile computing allows the user to access, create, process, store and communicate information from multiple locations. There are features which differentiate a mobile version from a 


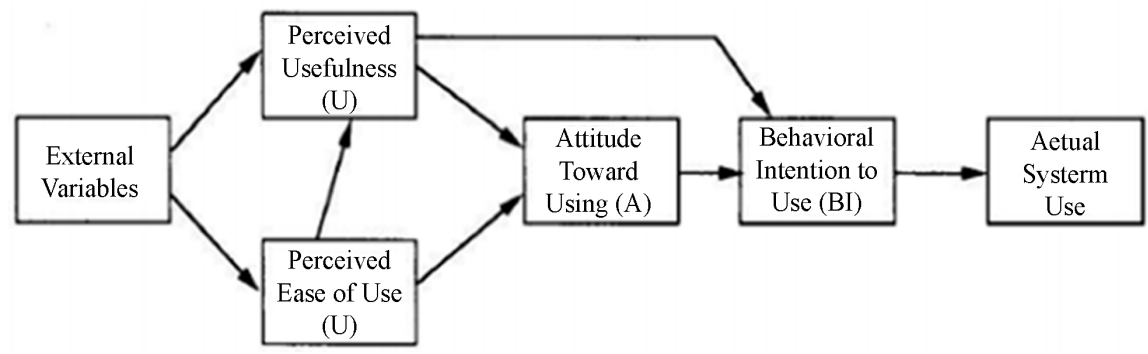

Figure 3. Technology acceptance model (TAM), Davis (1989).

conventional desktop app and are grouped into three categories, namely software, hardware, and communication [24].

Mobile apps were first popularised by Apple with the introduction of its App Store. The Apple App Store was followed by Google's Play Store in 2008, which sells Apps and acts as a storefront for developers to distribute their software to consumers. Today, Apple and Google both feature about 1.3 million apps [25].

The demand for mobile apps has increased due to the advancement of mobile computing and communication technology, thus different hardware manufacturers of mobile phones and tablets have therefore spurred developers to make different versions of each application for each type of device [16].

For successful mobile applications, functionality, reliability, flexibility, accessibility, portability, efficiency, maintainability, usability and responsiveness, are important characteristics to be observed iterated in line with the user's requirements and the quality characteristics specified in ISO 9126 [26].

The Mobile sites differ with the traditional desktop website including critical functions and features differs various ways which include; vertical instead of horizontal navigation; bars, tabs and hypertext; text and graphics; contextual and global navigation; footers; breadcrumbs; progress indicator and also localised and personal search [27].

The hardware, software, operating system and environment decide which communication medium is suitable for a particular mobile app. Advances in mobile apps, varied market and technological developments have dramatically benefited mobile developers by creating many new development opportunities and generating considerable revenues, with a growing number of mobile app portals [27].

\subsection{Software Development Life Cycle}

Holler [28] describes software development life cycle as the process of structuring and building a mobile app follows the Software Development Life Cycle (SDLC), a process used in the software industry to assure design and development of excellent quality software.

The SDLC has five phases that include the following:

- Planning, defining and analysing the user requirements

- Designing the product

- Developing the product by the created design 
- Testing the product

- Maintain the product.

\subsubsection{Waterfall Model}

The Waterfall Model is a sequential design process often used in software development in which progress is seen as flowing steadily downwards like a waterfall through the phases of conception, initiation, analysis, design, construction, testing, production/implementation and maintenance [6].

\subsubsection{Incremental Model}

From the Waterfall Model, comes the derivative, the incremental Model of which stages of the waterfall model are employed in a manner that any of the increments is used back as the input for the next increment. Therefore, with every increment, feedback is used in getting the next incremental product. The continuous processing of increments are only stopped until the complete product is delivered [6].

\subsubsection{Spiral Model}

Boehm [29] in his article "A Spiral Model of Software Development and Enhancement" explains that the Spiral Model was not the first model to discuss iterative development, but it was the first model to explain why the iteration matters. As originally envisioned, the iterations were typically six months to two years long. Each phase starts with a design goal and ends with the client (who may be internal), reviewing the progress thus far.

\subsubsection{Agile Development Model}

Agile software development is a group of iterative and incremental software development methodologies in which the requirements and solutions evolve through collaboration between self-organizing and cross-functional teams. This development model promotes adaptive planning, evolutionary development and delivery, and a time-boxed iterative approach, and encourages rapid and flexible response to change [30].

\subsubsection{Web Development}

Web app development has come a long way since the beginning of the World Wide Web. A number of technologies and programming languages are used to develop web apps. However, the technologies did not evolve as fast as the World Wide Web. Therefore, many efforts were made to improve the user experience and help developers to build faster and more powerful web apps.

\subsubsection{Model View Controller}

Reenskaug [31] first envisioned the Model View Controller (MVC) design pattern in the 1970s at the Xerox Parc. With MVC, the essential purpose is to bridge the gap between the human user's mental model and the digital model that exists in the computer. The model has benefits which include building the application in modules meaning isolating individual units from each other as much as poss- 
ible. Suffice to mention that this feature gives the application designer the advantage of understanding and modifying separate individual units without knowing everything about other units. The application is divided into three main categories, namely the model of the main app domain, the presentation of data in that model and user interaction [32]. The MVC design pattern is a good fit for web app development because it combines several technologies usually split into a set of layers.

1) The model is the part of the system that manages all tasks related to data, that is, validation, session state and control, and data source structure (database). The model greatly reduces the complexity of the code the developer needs to write [27] while the model layer is responsible for the business logic of an app, encapsulates methods for accessing data (databases, files, etc.) and makes a reusable class library available. Usually, a model is built with data abstraction in mind, validation and authentication [26].

2) The view is responsible for graphical user interface management. Therefore, forms, buttons, graphic elements and other hypertext Markup language (HTML) elements inside the app. Views can also be used to generate rich site summary (RSS) content for aggregators or flash presentations. By separating the design of the application from its logic, the risk of errors showing up when the designer alters the interface of the application by changing the logo or a table is reduced [32].

3) The controller is responsible for handling events, which can be triggered by either a user interacting with the app or a system process. A controller accepts requests, prepares the data for a response and establishes the format of the response. It interacts with the model in retrieving the needed data and generating the view. This process is also known as an action or a verb. When a request arrives at the server, the MVC framework dispatches it to a method in a controller based on the Universal Resource Locator (URL) [13] [27].

\subsubsection{Technologies}

Technologically, mobile platforms have developed from the legacy Global System for Mobile communication (GSM) to far more improved systems like second, third and fourth generations (2G, $3 \mathrm{G}$ and $4 \mathrm{G})$. Recently, both mobile and wireless systems have made significant advances in the form of Wireless Area Networks (WANs), Asynchronous Transfer Mode (ATM), Mobile Internet Protocol (IP), satellite based networks and wireless local loops [7] [33] [34]. Data connections normally used in mobile computing take forms like GSM, Code Division Multiple Access (CDMA), General Packet Radio Service (GPRS), Wideband Code Division Multiple Access (W-CDMA), EDGE and/or CDMA2000. Usually, these networks are available within the range of commercial communication towers. Satellite Internet access covers areas where cellular and Wireless Fidelity Wi-Fi are not available, and may be set up anywhere the user has a line of sight to the satellite's location which, for satellites in geostationary orbit, means having an unobstructed view of the southern sky. 


\section{Related Works}

The government of the Republic of Zambia, in the recent past has employed e-governance services to improve service delivery to citizens much easier and accessible. Such initiatives include; Zambia Integrated Land Management and Information System (ZILMIS), which is a new land management system aimed at tackling land malpractices. The system provides secure, transparent and traceable land transactions that help identify fraudulent practices. Further, an Integrated Financial Management System, IFMS, was implemented by the Zambian government to consolidate all the government transaction from one central point or screen. The objective of the IFMIS was to automate and integrate the public financial management systems to facilitate the efficient execution of all government financial management processes. This objective eliminates the risks and enhancement of financial control in all government spending agencies.

In the first quarter of 2019, the Parliament of Uganda launched a mobile app called Uganda Bungeni, which is available on Google Play and Apple Store and is aimed at enabling the public to trace the status of bills under the consideration of the house [35].

In the first quarter of 2019, the Parliament of Uganda launched a mobile app called Uganda Bungeni, which is available on Google Play and Apple Store and is aimed at enabling the public to trace the status of bills under the consideration of the house [36].

In 2017, the Parliament of Zimbabwe launched a mobile app called Parliament of Zimbabwe, on which parliamentary information and news is accessible [37].

The Parliament of the Republic of South Africa launched a Mobile App called My Parliament, which delivers information to Members of Parliament from any networked location in the world as and when needed, and enhances the way Members of Parliament perform their daily duties. The web application facilitates public participation through concurrent capture of submissions at public meetings [38].

The United Kingdom (UK) Parliament developed some parliamentary mobile apps, one of which is called My Constituency App. The app, which runs on Android phones, iPhones and iPads, shows the key statistics for each constituency, including election results, unemployment, youth unemployment and the population [39].

In New Delhi, India, a mobile app called Vote Chadni Chowk was developed by students of Delhi Technological University. The app allows voters to access information regarding their respective constituencies, such as location of polling stations and candidates [40].

The official mobile app for the parliament of Sri Lanka was developed by Bhasha Lanka (Pvt) Limited and launched in January 2016. The app, which is available for Android, iOS and Windows platforms, provides parliamentary information, including Member information, and other publications. Users are 
able to contact Members of Parliament using the mobile application [41].

\section{Methodology}

In this research, descriptive and quantitative research methods were adopted. Descriptive methods will enable the understanding of human and social problems, and paint a complex and holistic picture while reporting detailed views of information collected in a natural environment. A qualitative study is one that is conducted in a natural setting while quantitative research is the use of statistical analysis methods to make a connection between what is known and what can be learned [42].

In the development of mobile apps, this research adopted the Technology Acceptance Model (TAM). Davis [43] adapted the TRA to develop the TAM, which predicted the use of technology systems in the workplace. The TAM suggests that the perceived usefulness and ease of use of a new technology influence individuals' attitude towards, and use of the technology [43]. The TAM is a robust but parsimonious theory and it is useful for explaining particular information system apps. It has proven to be a useful theoretical model in the study and explanation of user behaviour in the implementation of an information system [44].

\subsection{Data Collection}

Data was collected using 53 survey self-administered questionnaires. A total of 60 questionnaires were distributed. A total number of 53 questionnaires were valid whilst 7 were invalid. The sample size from the 165 constituency offices was determined using the formula:

$$
n=N / 1+N\left(e^{2}\right)
$$

where $n$ is the sample size, $N$ is the population and e is the confidence level. Base on the $95 \%$ confidence level, it gave out a sample size of 60 .

To further understand how communication between the Members of Parliament and their electorates occurred, a mapping and modeling of business processes was done.

\subsection{Current Business Processes}

A member of a constituency wishing to present problems to the Member of Parliament approaches the Constituency Office and records the problem details, including;

- Date of Visit.

- Visitor's full name.

- Visitor's National Registration Number.

- Visitor's Phone Number.

- Problem description.

There are currently several ways by which a Member of Parliament gets in 
touch with the electorates. These are:

- Organising an Open Day, during which all electorates are invited to discuss issues affecting them in a face-to-face meeting with the Member as shown in Figure 4;

- Visiting the Constituency Office and reading the comments in the Visitors' Book as shown in Figure 5;

- Touring the constituency door-to-door to get views from the electorates and engaging district officials from different committees shown in Figure 6;

- Directly calling the Constituency Office to enquire get the issues recorded in the Visitors' Book as shown in Figure 7.

\subsection{Challenges}

In analysing the business processes depicted above, some of the challenges a Member of Parliament would encounter are:

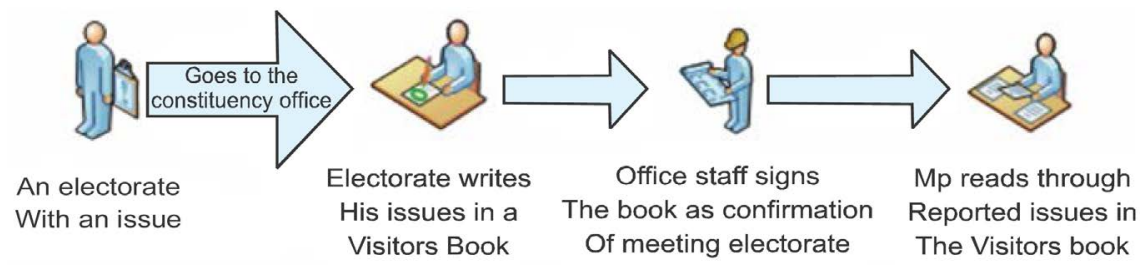

Figure 4. Open day scenario.

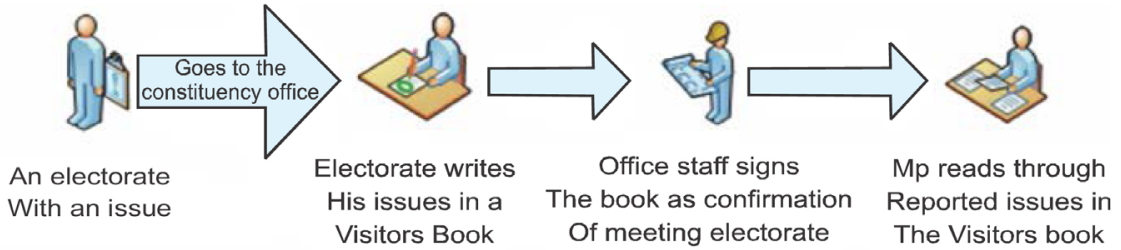

Figure 5. An electorate goes to the office to present issues.

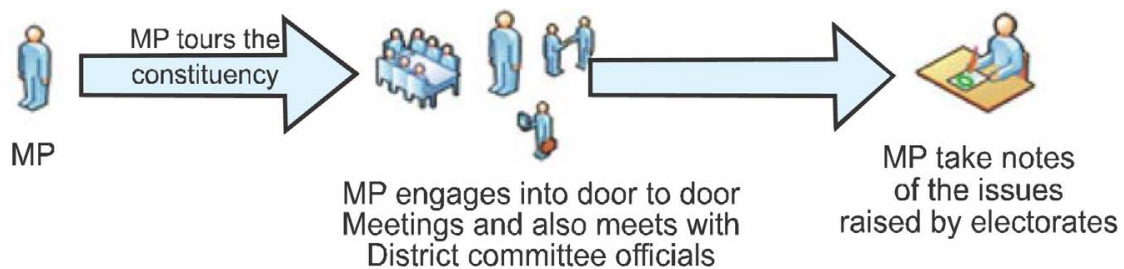

Figure 6. MP visiting the constituency, doing door to door meetings.

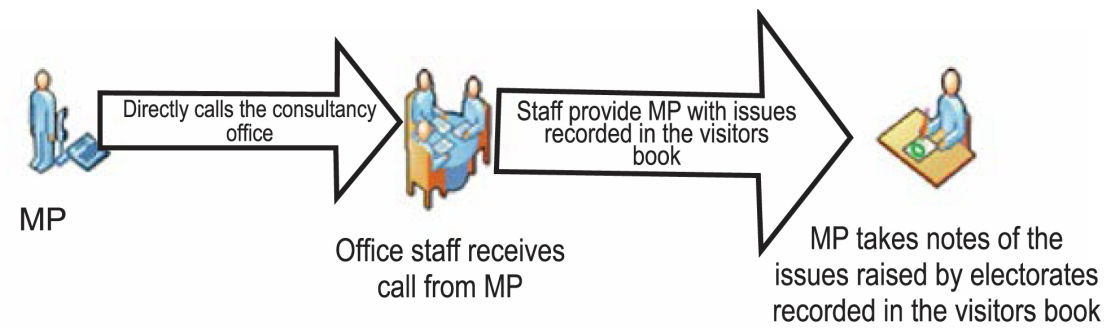

Figure 7. MP directly calling the constituency office. 
- People who would attend an open day would expect to be fed and given gifts, of which the office cannot afford.

- When the Member of Parliament visits the constituency on a fact finding mission, people expect him/her to show some form of gratitude to them by giving them money or other forms of gifts.

- In very remote constituencies, transportation costs are high on the part of the Member of Parliament (i.e. wear and tear of the motor vehicle).

- It is difficult to get statistics in a structured/ organised manner through a telephone conversation.

- Few people visit the Constituency Office to record their problems in the Visitors' Book and

- Sometimes, the electorates are afraid of raising very sensitive information at the Constituency Office.

\subsection{Proposed System (Model of Interaction)}

In the proposed model, firstly, Constituency Office staff and members of the constituency will have to install the app on their mobile devices. Thereafter, they will need to register on the system for them to be able to upload information, as shown in Figure 8. The information required from the user will include the date, first name, last name, National Registration Number (NRC) Number, name of constituency, phone number and problem description. After a user is registered and authenticated to a database, he/she will be presented with a menu on reporting and uploading the information to the cloud. For every report sent to the cloud, the system will generate a reference number that will be used to keep track of the entry. Additionally, as shown in Figure 9, there is a sequence of steps that involves the Member of Parliament. The application has to be installed on the Member of Parliament's mobile device. The system will, then, provide the Member of Parliament an interface to access the system and perform some data analytics. When the Member of Parliament logs into the system, he/she will have access to a list of the different types of reports and be able to upload responses to the cloud and directly to a registered user.

\subsection{Proposed Model for Development Process}

The agile practices are considered to be appropriate for the development of

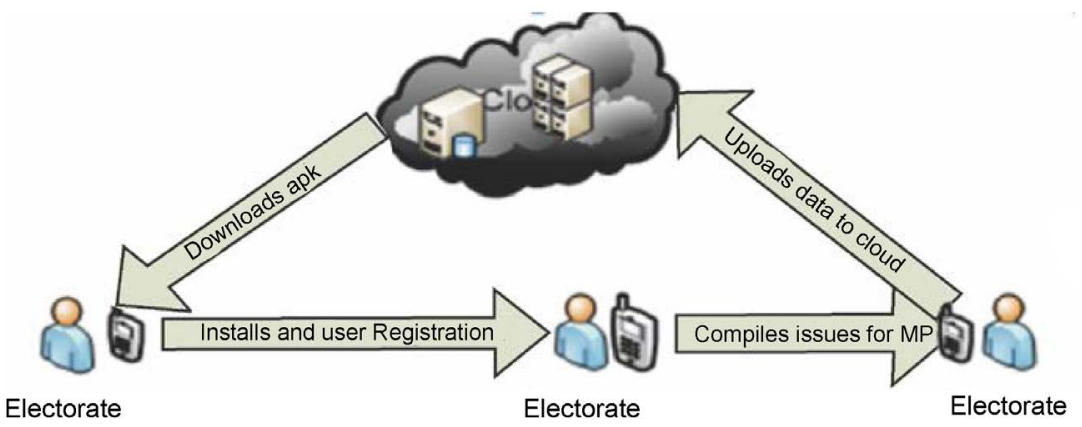

Figure 8. Proposed interaction between an electorate and the mobile app. 


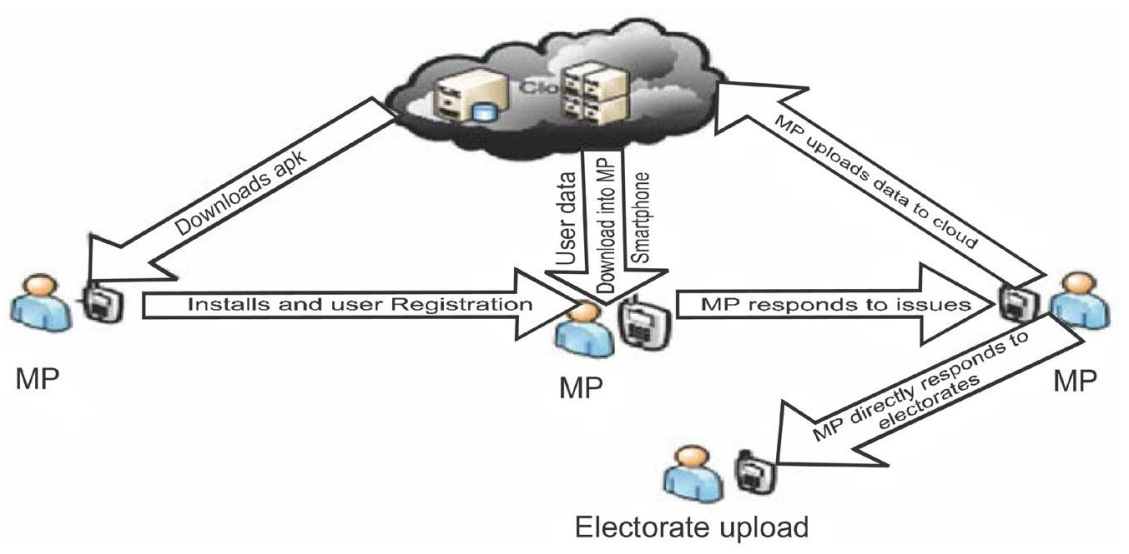

Figure 9. Proposed interaction between an Mp and the mobile app.

software for fast-paced markets, where satisfaction of user is achieved by the frequent release of software, user requirements can change spontaneously in the project and the delivery cycle is short (e.g. every couple of weeks). The agile principles and practices are also considered the most suitable for mobile app development because most mobile projects are short-term and require flexibility, as they usually have frequent change requests.

Research in the area suggests the necessity for software development processes to be tailored and modified to suit the requirements of mobile softwares. Agile methods have shown an ability to consistently adhere to the mobile software development process, offer a variety of solutions for mobile apps and assist service developers in need of high quality development processes [7] [45]. The mobile telecommunications industry consists of extremely complex, competitive and uncertain environments. Agile software development techniques seem to be a natural fit for mobile app development [46].

Agile techniques are suitable for the development of mobile apps because of their small teams, short deadlines, importance of usability, fast delivery and less complexity. The authors have suggested that seven months is enough time for agile methods to deliver a mobile app, including the experimentation and adaptive stages of the app; reliability leads to continued use of apps; extension of agile sprints into mobile app model and responsiveness to technological changes; rapidly accommodating customer feedback; a more thoughtful user experience; and phased rollout of feature sets [47].

Agile software development offers tremendous opportunities and value to mobile app development teams working to introduce a lightweight development process or scaled-back bureaucratic processes. The authors have emphasized the progress in mobile computer technology and rapid escalation of wireless networks in quality and quantity, which has brought in new apps and concerns. They also underline the promptness with which the industry needs to adopt systems development techniques that fulfill the special needs of this field [46].

The technology has been judged as being a "management fad" by numerous observers and that its claims of business improvement is measured on metrics 
defined by itself (e.g. velocity) [48]. The technology has also been criticized for its ineffectiveness when used in large organizations and certain types of projects, and proposed as an area that needs further research. Clearly, the technology has its limitations in distributed development efforts, offshore development and mission-critical systems where failure is not an option (e.g. software for air traffic control) [28].

A survey shows a clear link between agile methods and their use in a real-world setting, leading to a decline in the idea that agile practices are a silver bullet [32] [49].

\section{Results}

\subsection{System Architecture}

Figure 10 shows the architecture of the proposed system.

\subsection{Demographic Data Analysis}

A questionnaire was administered to 60 respondents from different constituencies. 53 questionnaires were valid representing (88.3\%) response rate, whilst 7 questionnaires were invalid representing $11.66 \%$. The respondents consisted of $57 \%$ males and $43 \%$ females, as shown in Table 1 . Three age groups were sampled, with the following representations:
1) 20 - 30 years $(21 \%)$;
2) 30 - 40 years $(51 \%)$; and
3) 40 - 50 years $(28 \%)$.

as shown in Table 2.

Figure 11 is an adaptation of the TAM. It shows how perceived usefulness, perceived ease of use and perceived risk of acceptance or adoption of the proposed mobile application.

\subsection{Technology Acceptance Model Results Analysis}

The TAM has five variables. However, in this research, a modified model with

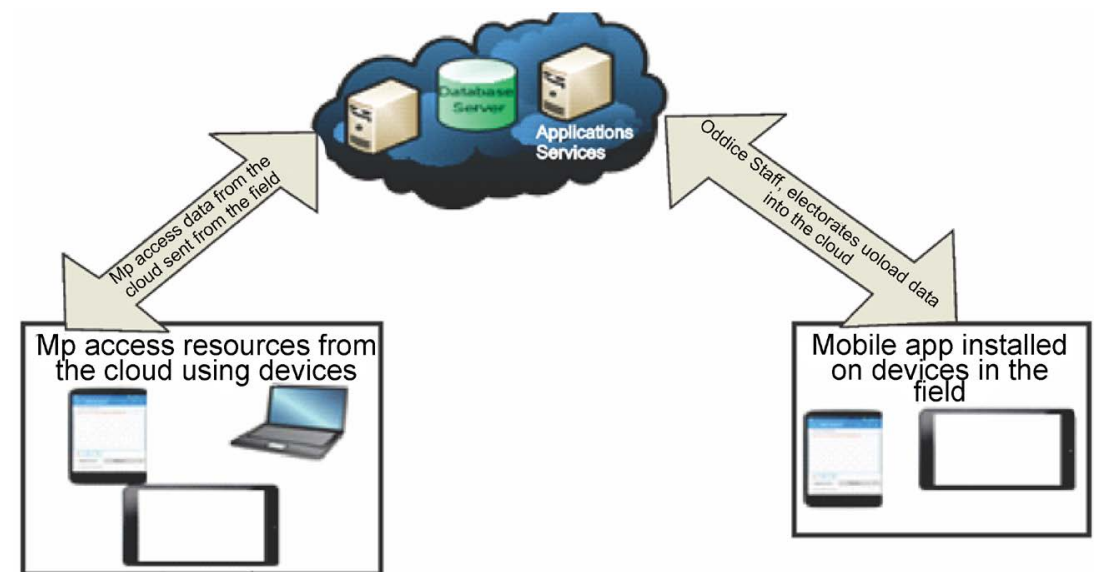

Figure 10. Architecture of the system. 
Table 1. Gender representation.

\begin{tabular}{ccccc}
\hline & Gender & Percent & Valid Percent & Cumulative Percentage \\
\hline Male & 30 & 56.6 & 56.6 & 56.6 \\
Female & 23 & 43.4 & 43.4 & 100 \\
Total & 53 & 100 & 100 & \\
\hline
\end{tabular}

Table 2. Age group distribution.

\begin{tabular}{ccccc}
\hline Age Group & Frequency & Percent & Valid Percent & Cumulative Percent \\
\hline $20-30$ & 11 & 20.8 & 20.8 & 20.8 \\
$30-40$ & 27 & 50.9 & 50.6 & 71.7 \\
$40-50$ & 15 & 28.3 & 28.3 & 100 \\
Total & 53 & 100 & 100 & \\
\hline
\end{tabular}

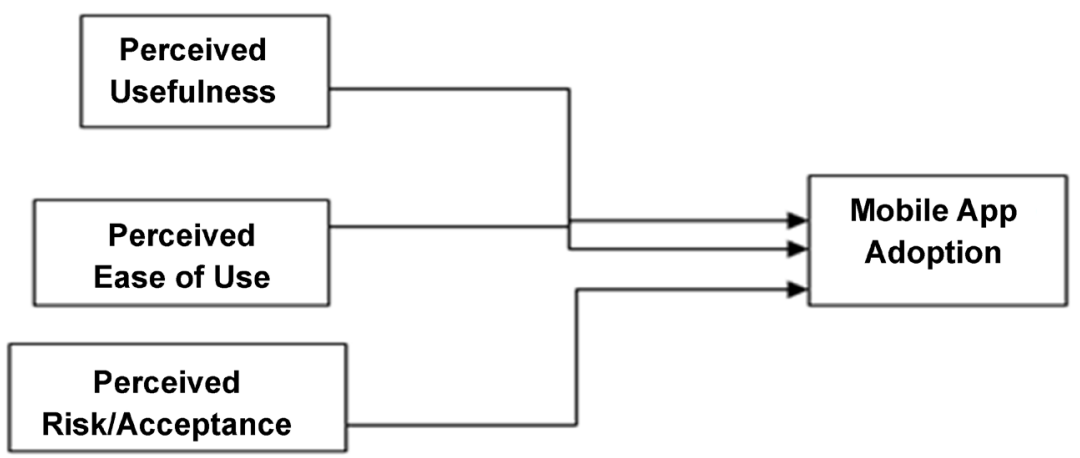

Figure 11. Adopted model for the research.

only three variables was adopted in [50] with only three variables, namely perceived usefulness, perceived ease of use and perceived acceptance risk.

\subsection{Instrument Reliability}

The recommendation in this research was based on the output of the instrument of data collection, which was a questionnaire. Therefore, the reliability test was measured in Chronbach Alpha using the Statistical Package for the Social Sciences (SPSS). The statistical software analysed the internal consistency and reliability of the questionnaire. The questionnaire was designed with a Likert scale of 3 scales (i.e. 1 = "None of the above", 2 = "No", and 3 = "Yes"). The data analysis techniques used in this research are descriptive and statistical analysis, as indicated in the tables below. From Table 3, it can be seen that reliability has an index of 0.896. Therefore, since the Cronbach Alpha of all the three variables is more than 0.6 , the instrument was reliable.

Two of the variables used in the research, perceived usefulness and perceived ease of use, which influence the acceptance/adoption of the mobile app, are influenced by external variables that include socio-cultural and political factors. Below is the statistical analysis using the TAM. Table 4 shows that $67.9 \%$ of the 
Table 3. Reliability of the instrument.

\begin{tabular}{ccc}
\hline Cronbach's Alpha & Cronbach's Alpha Based on Standardized items & N of items \\
\hline 0.986 & 0.987 & 3 \\
\hline
\end{tabular}

Table 4. Perceived usefulness.

\begin{tabular}{ccccc}
\hline & Frequency & Percent & Valid Percent & Cumulative Percent \\
\hline None of the above & 5 & 9.4 & 9.4 & 9.4 \\
No & 12 & 22.6 & 22.6 & 32.1 \\
Yes & 36 & 67.9 & 67.9 & 100 \\
Total & 53 & 100 & 100 & \\
\hline
\end{tabular}

participants in the survey indicated that the app would be useful, $22.6 \%$ of the respondents felt the app would not be useful while $9.4 \%$ did not express an opinion. Table 5 shows that $67.9 \%$ of respondents thought that the app would be easy to use, $18.9 \%$ thought it would be difficult to use while $13.2 \%$ did not express an opinion on the variable. Table 6 shows that $66 \%$ of respondents would adopt the app, $24.5 \%$ would reject it while $9.4 \%$ did not take a position.

\subsection{Correlation Coefficients}

Correlation is a technique used to investigate relationships among a set of variables. The Pearson's correlation coefficient $(r)$ measures the strength of the association between variables. In this research, the variables considered for the Pearson's correlation coefficient were perceived usefulness and perceived ease of use. Table 7 shows that the results of the analysis of the variables using the Pearson correlation shows a strong positive correlation between them $(r=0.965$, $\mathrm{n}=53, \mathrm{p}<0.001)$. Table 8 summarizes the regression and confirms the correlation value depicted in Table 7.

\subsection{Statistical Significance (P-Values)}

Statistical significance is the likelihood that the difference in conversion rates between a given variation and the baseline is not due to random chance. It is the probability of finding a given deviation from the null hypothesis, and is often referred to as the $\mathrm{P}$-value or $\mathrm{P}$, with a small $\mathrm{p}$-value $(\mathrm{p}<0.05)$ meaning that the research data is unlikely under the null hypothesis. This means there is strong evidence against the null hypothesis and, therefore, nullifies the hypothesis. On the other hand, a large P-value (>0.05) indicates weak evidence against the null hypothesis, thereby nullifying the null hypothesis. P-values very close to the cut off mark of 0.05 are considered marginal, meaning the result can fall on either side of the correlation divide. $\mathrm{P}$-values must be reported in order to allow readers draw their own conclusions

Therefore, the hypothesis for this research is that if a mobile application for interaction is developed, there will be easy access to information between Members 
Table 5. Perceived ease of use.

\begin{tabular}{ccccc}
\hline & Frequency & Percent & Valid Percent & Cumulative Percent \\
\hline None of the above & 7 & 13.2 & 13.2 & 13.2 \\
No & 10 & 18.9 & 18.9 & 32.1 \\
Yes & 36 & 67.9 & 67.9 & 100 \\
Total & 53 & 100 & 100 & \\
\hline
\end{tabular}

Table 6. Acceptance of mobile app.

\begin{tabular}{ccccc}
\hline & Frequency & Percent & Valid Percent & Cumulative Percent \\
\hline None of the above & 5 & 9.4 & 9.4 & 9.4 \\
No & 13 & 24.5 & 24.5 & 34 \\
Yes & 35 & 66 & 66 & 100 \\
Total & 53 & 100 & 100 & \\
\hline
\end{tabular}

Table 7. Correlation.

\begin{tabular}{cccc}
\hline & & $\begin{array}{c}\text { Perceived Usefulness } \\
\text { of the new Mobile } \\
\text { application }\end{array}$ & $\begin{array}{c}\text { Perceived Ease of } \\
\text { Use of the New } \\
\text { Mobile application }\end{array}$ \\
\hline $\begin{array}{c}\text { Perceived Usefulness of the new } \\
\text { Mobile application }\end{array}$ & Pearson Correlation & 1 & $0.965^{* *}$ \\
Sig. (2-tailed) & $\mathrm{N}$ & 53 & 0.000 \\
$\begin{array}{c}\text { Perceived Ease of Use of the New } \\
\text { Mobile application }\end{array}$ & Pearson Correlation & $0.965^{* *}$ & 53 \\
& Sig. (2-tailed) & 0.000 & 1 \\
\hline
\end{tabular}

${ }^{* *}$ Correlation is significant at the 0.01 level (2-tailed).

Table 8. Regression summary.

\begin{tabular}{ccccc}
\hline \multicolumn{5}{c}{ Model Summary } \\
\hline Model & $\mathrm{R}$ & R Square & Adjusted R Square & Std. Error of the Estimate \\
\hline 1 & $0.965^{\mathrm{a}}$ & 0.931 & 0.930 & 0.191 \\
\hline
\end{tabular}

of Parliament and the electorates. Therefore, the null hypothesis is that the electorates will not adopt a mobile app developed to enhance their communication with their Members of Parliament (perceived usefulness) whilst the alternative hypothesis in our case is the opposite in that the development of the mobile application will enhance communication between members of parliament and electorates. Table 9 shows a $\mathrm{p}$-value of $\mathrm{p}<0.001$, which indicates significant statistical evidence against the null hypothesis. So, the null hypothesis is rejected and the alternative hypothesis adopted, which is that the electorates will adopt the app when developed. 
Table 9. Anova.

\begin{tabular}{ccccccc}
\hline \multicolumn{7}{c}{ ANOVA $^{\mathrm{b}}$} \\
\hline \multicolumn{1}{c}{ Model } & Sum of Squares & df & Mean Square & F & Sig. \\
\hline \multirow{2}{*}{1} & Regression & 25.267 & 1 & 25.267 & 691.074 & $0.000^{\mathrm{a}}$ \\
& Residual & 1.865 & 51 & 0.037 & & \\
& Total & 27.132 & 52 & & & \\
\hline
\end{tabular}

\section{Discussion}

The main aim of the research was to establish the baseline on the challenges Members of Parliament face when interacting with their Constituency Office staff, which goes in the field and also challenges encountered to further interact with the electorates. The TAM was used to measure the extent to which the proposed mobile app would be accepted by users. This exercise also included analyzing the current business processes among Members of Parliament, Constituency Office staff and the electorates. It also involved the designing and development of a prototype model of the mobile application to address the noted challenges.

\section{Conclusion}

This research was a study of the business process to establish the main challenges Members of Parliament face in their interactions with Constituency Office staff and the electorates. The data collected indicate that there is a huge communication gap between the Member of Parliament and the electorates, leading to the Member of Parliament having difficulties understanding what is on the ground in his or her constituency. Further, due to the breakdown of communication, it is difficult for the Member of Parliament to have statistics on the many issues raised in the constituency. The mobile application addresses all these issues and avails all the necessary statistical data to the MP's.

\section{Acknowledgements}

The authors wish to acknowledge all the participants who took part in the research study.

\section{Conflicts of Interest}

The authors declare no conflicts of interest regarding the publication of this paper.

\section{References}

[1] Phiri, A.H., Phiri, J. and Mwanza, S. (2019) Developing an SMS-Based Mobile Application in the Food Supply Chain in Zambia. International Journal of Wireless and Mobile Computing, 17, 167-186. https://doi.org/10.1504/IJWMC.2019.101428

[2] Mpolokoso, A. and Phiri, J. (2018) Managing Customary Land Conflicts and De- 
marcations Using Mobile Applications Tools: A Case Study of Zambia. International Journal of Wireless and Mobile Computing, 15, 323-334. https://doi.org/10.1504/IJWMC.2018.097165

[3] World Bank (1989) Sub-Saharan Africa: From Crisis to Sustainable Growth. World Bank, Washington DC.

[4] Chowdhury, N. and Skarstedt, C.E. (2005) The Principle of Good Governance. Draft Working Paper, CISDL Recent Developments in International Law Related to Sustainable Development Series. UK, PP, Oxford.

[5] Rhodes, R.A.W. (1996) The New Governance: Governing without Government. Political Studies, 44, 652-667. https://doi.org/10.1111/j.1467-9248.1996.tb01747.x

[6] Leavitt, N. (2009) Is Cloud Computing Really Ready for Prime Time? Computer, 42, 15-20. https://doi.org/10.1109/MC.2009.20

[7] Noerpel, A.R. and Lin, Y.B. (1998) Wireless Local Loop: Architecture, Technologies, and Services. IEEE Personal Communications Magazine, 5, 74-80. https://doi.org/10.1109/98.683743

[8] Ntaliani, M., Costopoulou, C. and Karetsos, S. (2008) Mobile Government: A Challenge for Agriculture. Government Information Quarterly, 25, 699-716. https://doi.org/10.1016/j.giq.2007.04.010

[9] Hellström, J. (2008) Mobile Phones for Good Governance-Challenges and Way Forward. Stockholm University, UPGRAID, Stockholm.

[10] Kuscu, M.H., Kushchu, I. and Yu, B. (2008) Introducing Mobile Government. In: Anttiroiko, A., Ed., Electronic Government. Concepts, Methodologies, Tools, and Applications, IGI Global, Hershey, 227-235. https://doi.org/10.4018/978-1-59904-947-2.ch020

[11] Blomstrom, M. and Kokko, A. (1998) Multinational Corporations and Spillovers. Journal of Economic Surveys, 12, 247-277. https://doi.org/10.1111/1467-6419.00056

[12] Reddy, N.M. and Zhao, L. (1990) International Technology Transfer. A Review. Research Policy, 19, 285-307. https://doi.org/10.1016/0048-7333(90)90015-X

[13] Stratmann, E., Ousterhout, J. and Madan, S. (2011) Integrating Long Polling with an MVC Framework. Proceedings of the 2nd USENIX Conference on Web Application Development, Portland, 15-16 June 2011, 10.

[14] Oye, N.D., Iahad, N.A. and AbRahim, N. (2012) The History of UTAUT Model and Its Impact on ICT Acceptance and Usage by Academicians. Educational Information Technology, 19, 251-270.

[15] Kallioja, M., Louho, R. and Oittinen, P. (2006) Factors Affecting the Use of Hybrid Media Applications. Graphic Arts in Finland, 35, 11-21.

[16] Dillon, A. and Morris, C. (2001) User Acceptance of Information Technology. In: Karwowski, W., Ed., Encyclopedia of Human Factors and Ergonomics, Taylor and Francis, London, 5.

[17] Marche, S. and McNiven, J.D. (2003) E-Government and E-Governance. The Future Isn't What It Used to Be. Canadian Journal of Administrative Sciences, 20, 74-86. https://doi.org/10.1111/j.1936-4490.2003.tb00306.x

[18] Baenbasat, I. and Barki, H. (2007) TAM. Journal of the AIS, 8, 211-218. https://doi.org/10.17705/1jais.00126

[19] Fishbein, M. and Ajzen, I. (1975) Belief, Attitude, Intention, and Behavior: An Introduction to Theory and Research. Addison-Wesley, Reading.

[20] Daka, G.C. and Phiri, J. (2019) Factors Driving the Adoption of E-Banking Services 
Based on the UTAUT Model. International Journal of Business and Management, 14, 43. https://doi.org/10.5539/ijbm.v14n6p43

[21] Venkatesh, V., Morris, M.G., Davis, G.B. and Davis, F.D. (2003) User Acceptance of Information Technology: Toward a Unified View. MIS Quarterly, 27, 425-478. https://doi.org/10.2307/30036540

[22] Soneka, P.N. and Phiri, J. (2019) A Model for Improving E-Tax Systems Adoption in Rural Zambia Based on the TAM Model. Open Journal of Business and Management, 7, 908-918. https://doi.org/10.4236/ojbm.2019.72062

[23] Clement, J. (2019) Mobile App Usage-Statistics \& Facts. Statista. https://www.statista.com/topics/1002/mobile-app-usage

[24] Diero, L., Rotich, K., Bii, J., Mamlin, B.W., Einterz, R.M., Kalamai, I.Z. and Tierney, W.M. (2006) A Computer-Based Medical Record System and Personal Digital Assistants to Assess and Follow Patients with Respiratory Tract Infections Visiting a Rural Kenyan Health Centre. BMC Medical Informatics and Decision Making, 6, 21. https://doi.org/10.1186/1472-6947-6-21

[25] Pu, Q.K. and Li, H.H. (2012) Mobile Navigation System. U.S. Patent 8,200,426, infoGation Corp.

[26] Cleland-Huang, J. (2012) Traceability in Agile Projects. In: Software and Systems Traceability, Springer, London, 265-275. https://doi.org/10.1007/978-1-4471-2239-5_12

[27] Freeman, A. and Sanderson, S. (2011) Pro ASP.NET MVC 3 Framework. Springer, Berlin. https://doi.org/10.1007/978-1-4302-3405-0

[28] Holler, R. (2011) Mobile Application Development: A Natural Fit with Agile Methodologies. Version One, White Paper. http://www.versionone.com/pdf/mobiledevelopment.pdf

[29] Boehm, B. (1986) A Spiral Model of Software Development and Enhancement. ACM SIGSOFT Software Engineering Notes, 11, 14-24. https://doi.org/10.1145/12944.12948

[30] Flora, H.K. and Chande, S.V. (2013) A Review and Analysis on Mobile Application Development Processes Using Agile Methodologies. International Journal of Research in Computer Science, 3, 9.

[31] Reenskaug, T.M.H. (1979) The Original MVC Reports.

[32] Gilmore, W.J. (2009) Easy PHP Websites. W.J. Gilmore, Columbus.

[33] LaMaire, R.O., Krishna, A. and Bhagwat, P. (1996) Wireless LAN and Mobile Networking: Standards and Future Directions. IEEE Communications Magazine, 34, 86-94. https://doi.org/10.1109/35.533925

[34] Raychaudhuri, D. and Wilson, N.D. (1994) ATM-Based Transport Architecture for Multi Services Wireless Personal Communication Networks. IEEE Journal on Selected Areas in Communications, 12, 1401-1414. https://doi.org/10.1109/49.329336

[35] (2019) Parliament Launches App for Tracking Status of Bills. https://www.sautitech.com/digital/mps-launch-uganda-bungeni-app

[36] Lead, B. (2018) OrderPaper Launches ConsTrack Mobile App on Constituency Projects.

https://www.orderpaper.ng/orderpaper-launches-constrack-mobile-app-on-constit uency-projects

[37] Mail, T.S. (n.d.) Parliament of Zimbabwe Launches Mobile App. https://www.sundaymail.co.zw/parliament-of-zimbabwe-launches-mobile-app 
[38] (2013) Parliament Gets Tech Savvy with an App. eNCA. https://www.enca.com/south-africa-technology/parliament-gets-tech-savvy-app-0

[39] W4MP Editor (2015) Parliamentary Mobile Apps. http://www.w4mp.org/2015/05/11/parliamentary-apps

[40] Pandey, G. (2019) Delhi EC Launches App for Chandni Chowk Voters. https://www.asianage.com/metros/delhi/260419/delhi-ec-launches-app-for-chandni -chowk-voters.html

[41] Parliament of Sri Lanka (2016) Parliament of Sri Lanka Unveils Its Official Mobile App. https://www.parliament.lk/news-en/view/1130/?category=6\&lang=en

[42] Flora, H.K., Wang, X. and Chande, S.V. (2014) An Investigation into Mobile Application Development Processes: Challenges and Best Practices. International Journal of Modern Education and Computer Science, 6, 1-9. https://doi.org/10.5815/ijmecs.2014.06.01

[43] Davis, F.D. (1989) Perceived Usefulness, Perceived Ease of Use, and User Acceptance of Information Technology. MIS Quarterly, 13, 319-339.

https://doi.org/10.2307/249008

[44] Chen, S., Li, S. and Li, C. (2011) Recent Related Research in Technology Acceptance Model: A literature Review. Australian Journal of Business and Management Research, 1, 124-127.

[45] Abrahamsson, P., Hanhineva, A., Hulkko, H., Ihme, T., Jälinoja, J. and Korkala, M.M. (2004) Mobile-D: An Agile Approach for Mobile Application Development. Companion to the 19th Annual ACM SIGPLAN Conference on Object-Oriented Programming Systems, Languages, and Applications, Vancouver, 24-28 October 2004, 174-175. https://doi.org/10.1145/1028664.1028736

[46] Fowler, M. (2006) Using an Agile Software Process with Offshore Development. http://martinfowler.com/articles/agileOffshore.html

[47] Honavar, V., Miller, L. and Wong, J. (1998) Distributed Knowledge Networks. Information Technology Conference Information Environment for the Future, Syracuse, 3 September 1998, 87-90. https://doi.org/10.1109/IT.1998.713388

[48] Janes, A.A. and Succi, G. (2012) The Dark Side of Agile Software Development. In: Proceedings of the ACM International Symposium on New Ideas, New Paradigms, and Reflections on Programming and Software, ACM, New York, 215-228. https://doi.org/10.1145/2384592.2384612

[49] Corral, L., Sillitti, A. and Succi, G. (2013) Software Development Processes for Mobile Systems: Is Agile Really Taking over the Business? 1st International Workshop on the Engineering of Mobile-Enabled Systems, San Francisco, 25 May 2013, 19-24. https://doi.org/10.1109/MOBS.2013.6614218

[50] Gahtani, S.A. (2001) The Applicability of TAM outside North America. An Empirical Test in United Kingdom. Information Resource Management Journal, 14, 37-46. https://doi.org/10.4018/irmj.2001070104 